\title{
Adherence to treatment and
}

\section{anticoagulation control in vitamin}

$K$ antagonists-treated patients: an

\section{a large Italian population}

Luca Degli Esposti ( ${ }^{(1)}$, Diego Sangiorgi ${ }^{(1)}$, Giuseppe Di Pasquale ${ }^{(2)}$, Gian Franco Gensini ${ }^{(3,4)}$, Ido Iori ${ }^{(5)}$, Stefano Buda (l), Ezio Degli Esposti(l) on the behalf of the Study Group

\begin{abstract}
Oral anticoagulant therapy is essential for the treatment and prevention of many thromboembolic disorders. The aim of the present study is to evaluate the level of anticoagulation intensity in patients treated with vitamin K antagonists (VKAs) in a clinical practice setting and to explore the relationship between anticoagulation intensity and adherence to VKA treatment. We conducted a retrospective cohort study using the administrative databases of three Italian Local Health Units. Patients were enrolled if they had filled at least one prescription for VKAs (ATC code B01AA) between January $1^{\text {st }}, 2007$ and June 30 $30^{\text {th }}, 2008$. In the same period all determinations of the international normalised ratio (INR) were collected. The parameters evaluated were anticoagulation control and adherence to VKA treatment.

The survey showed that only $47.9 \%$ and $56.3 \%$ of INR determinations, in VKA naïve and established patients respectively, were into the recommended range (2.0-3.0). Moreover, the percentage of INR determination below the recommended range was higher than the percentage of INR determination above the recommended range for both naïve and established patients. Moreover, adherence to VKA treatment was poor both in naïve and established patients and, consequently, anticoagulation control is poor. Also in patients with the highest adherence to VKA treatment, only about $60 \%$ of INR determinations were into the recommended range. Our findings evidence that the anticoagulation control in clinical practice settings is still unsatisfactory and it is necessary to evaluate interventions to increase the amount of time at which patients' INR are within the recommended range.
\end{abstract}

Keywords: adherence to treatment, anticoagulation control, INR, vitamin K antagonists, administrative databases

Farmeconomia e percorsi terapeutici 2011; 12(2): 53-59

\section{INTRODUCTION}

Oral anticoagulant therapy is essential for the treatment and prevention of many thromboembolic disorders [1-3]. In atrial fibrillation, long term anticoagulation treatment can reduce the annual risk of stroke by two thirds $[4,5]$. Such treatment compares favourably with the alternative, aspirin treatment [6]. However, the pharmacokinetic profile of vitamin $\mathrm{K}$ antagonists (VKAs) is complex [7], and monitoring is required to avoid both thromboembolic events associated with low intensity anticoagulation and haemorrhagic complications associated with higher intensity. Target levels of oral anticoagulation are disease specific and measured with the international normalised ratio (INR). However, in most of therapeutic indications, the recommended range is 2.0-3.0 [8]. To attain INR values within this range, patients are routinely monitored and their VKA doses are adjusted when necessary. It is well known that long term stability is difficult to achieve because of unexpected fluctuations of the INR values in patients, which can be attributed to numerous factors including change in diet, poor adherence to treatment, alcohol consumption, seasonal variations, and drug to drug interactions $[9,10]$.

The aim of this study is to evaluate the level of anticoagulation control in patients treated with VKA for various indications in a clinical practice setting and to explore the relationship between anticoagulation control and adherence to VKA treatment.

\section{PATIENTS AND METHODS}

\section{Sources of data}

The data we used were retrieved from three different administrative databases of three Local Health Units (LHU) located in the centre
${ }^{(1)}$ CliCon S.r.l. Health, Economics and Outcomes Research, Ravenna

(2)Unità Operativa di Cardiologia. Ospedale Maggiore, Bologna

${ }^{(3)}$ Dipartimento di Area Critica MedicoChirurgica, Università degli Studi di Firenze, Azienda OspedalieroUniversitaria, Careggi ${ }^{(4)}$ Fondazione Don Carlo Gnocchi, Onlus IRCCS, Impruneta, Firenze ${ }^{(5)}$ Medicina Interna I, Centro Emostasi e Trombosi-Stroke Unit, Azienda Ospedaliera A.S.M.N., Reggio Emilia

Corresponding author

Luca Degli Esposti

luca.degliesposti@clicon.it 
and north of Italy and including approximately 774,000 beneficiaries: "Health-assisted subjects' Database", containing patients' demographic data; "Medications Prescription Database", providing information for each medication prescription such as the prescribing physician's number, the Anatomical-TherapeuticChemical (ATC) code of the drug purchased, the number of packs, the number of units per pack, the dosages, the unit cost per pack and the prescription date; and "Laboratory test values database", which includes the date of administration for laboratory test, the type of laboratory test and description, and the laboratory test result. The patient code in each database permitted electronic linking among all three databases. In order to guarantee patient privacy, each subject was assigned an anonymous univocal numeric code. The researchers weren't provided with identifiers related to patients. The local Ethics Committee of each participating LHUs approved this study.

\section{Cohort definition}

This was a retrospective cohort study, which included all relevant medication prescription and laboratory test data over the study period for both naïve and established VKA users. Patients were enrolled if they had filled at least one prescription for VKAs (ATC code B01AA) between January $1^{\text {st }}, 2007$ and June $30^{\text {th }}, 2008$ (enrolment period). The enrolment date of a given study subject was defined as the first date on which a patient filled a prescription for one of these drugs during the enrolment period. Naïve/ established patients were classified according to the absence/presence of prescriptions for VKAs filled during the year preceding the enrolment date. Patients who were transferred to another LHU or died or had no INR determinations during the year following the enrolment date were excluded.

\section{Adherence to treatment}

Adherence to treatment was calculated as the sum of "adequately dosed" days for VKAs divided by the duration in days of the follow up period (365) multiplied by 100 . Tablets in each prescription were divided by the elapsed time in days up to the following prescription. If the average number of tablets per day was in the range $0.5-2.0$, the number of days up to the following prescription was classified as "adequately dosed" for VKAs. Tablets prescribed into the last prescription contributed only for those accountable until the end the follow up period.

\section{Anticoagulation control}

Anticoagulation control was calculated as the sum of INR determinations in the range 2.0-3.0 divided by the overall number of INR determinations multiplied by 100 . In order to avoid potential confounding effects of low or high number of INR determinations, the relationship between anticoagulation control and adherence to treatment was studied also in patients within 25 and 75 percentile of INR determinations.
Table I

Concurrent antithrombotic drugs and number of INR determinations in 10,883 VKAs treated patients

\begin{tabular}{|c|c|c|c|c|c|}
\hline & Heparins & $\begin{array}{l}\text { Antiplatelet } \\
\text { agents }\end{array}$ & $\begin{array}{c}\text { Other } \\
\text { antithrombotic } \\
\text { agents }\end{array}$ & $\begin{array}{l}\text { Number of } \\
\text { patients (\%) }\end{array}$ & $\begin{array}{l}\text { INR determination } \\
\text { (median, percentile } \\
\text { 25-percentile } 75 \text { ) }\end{array}$ \\
\hline \multirow{6}{*}{$\begin{array}{l}\text { VKA-naïve } \\
\text { patients }\end{array}$} & & & & $1,923(62.5)$ & $19(10-29)$ \\
\hline & & & • & $11(0.4)$ & $26(18-33)$ \\
\hline & & • & & $620(20.2)$ & $14(6-23)$ \\
\hline & & • & $\bullet$ & $3(0.1)$ & $6(5-12)$ \\
\hline & • & & & $382(12.4)$ & $19(11-29)$ \\
\hline & - & - & & $136(4.4)$ & $15(7-22)$ \\
\hline Total & & & & $3,075(100.0)$ & $18(8-28)$ \\
\hline \multirow{8}{*}{$\begin{array}{l}\text { VKA- } \\
\text { established } \\
\text { patients }\end{array}$} & & & & $6,442(83.0)$ & $16(12-25)$ \\
\hline & & & - & $7(0.1)$ & $20(11-44)$ \\
\hline & & $\bullet$ & & $628(8.1)$ & $15(7-24)$ \\
\hline & & $\bullet$ & • & $3(0.1)$ & $28(1-31)$ \\
\hline & $\bullet$ & & & $587(7.6)$ & $16(10-25)$ \\
\hline & - & & $\bullet$ & $2(0.1)$ & $24.5(14-35)$ \\
\hline & - & - & & $89(1.1)$ & $11(6-18.5)$ \\
\hline & - & - & - & $0(0.0)$ & $\ldots$ \\
\hline Total & & & & $7,758(100.0)$ & $16(12-25)$ \\
\hline
\end{tabular}




\section{Statistical analysis}

Data were summarised as mean \pm standard deviation (SD) or median (25-75 percentile) for continuous variable and as numbers (percentages) of subjects for categorical variables. Pearson's chi-square and one-way ANOVA tests were used to evaluate differences in baseline characteristics across adherence levels. Multivariable median regression was used to estimate beta coefficient $(\beta)$ and $95 \%$ confidence intervals (CIs) of achieving anticoagulation control as a function of adherence categories. To adjust for potential confounders, in the multivariable model we included age, gender, and presence of thrombolytic drugs (yes/no) - at least two prescriptions in the follow up period of heparin (ATC code B01AB), antiplatelet agents (ATC code B01AC), and concurrent antithrombotic therapy (ATC code B01AD - enzymes, ATC code B01AE - direct thrombin inhibitors, ATC code B01AX - other antithrombotic agents). Two-tailed p-values less than 0.05 were considered statistically significant. All analyses were conducted using SPSS for Windows, version 15.0.

\section{RESULTS}

A total of 16,339 patients were enrolled in the study. Of whom, 5,506 patients $(33.7 \%$ of enrolled subjects) were excluded: $82(0.5 \%)$ because they were transferred to another LHU, $1,421(8.7 \%)$ because they died and 4,003 $(24.5 \%)$ because they had not INR determinations during the follow up period. A total of 10,833 patients were included in the study, 5,531 men (51.0\%) and 5,302 women (49.0\%), with a mean age of $75.1 \pm 10.6$ (range 18-101) years. Most of the patients were aged 70-89 years old $(67.6 \%$ of men and $75.9 \%$ of women). Among included patients, 3,075 (28.4\%) were classified as naïve and 7,758 (71.6\%) as established. Naïve patients were younger than established ones $(73.5 \pm 12.0$ versus $75.8 \pm 9.9)$ and prevalently male (51.0\%). Concurrent antithrombotic drugs and frequency of INR determinations are presented in Table I.

Most patients showed no concurrent antithrombotic drug combined with VKAs both in naïve $(62.5 \%)$ and in established patients $(59.5 \%)$. Concurrent use of heparins or antiplatelet agents resulted, respectively, in $12.4 \%$ and $20.2 \%$ of naïve patients and in $7.6 \%$ and $8.1 \%$ of established patients (Table I). The median number of INR determination was 17 (11-26) in the overall included cohort, ranging from 18 (8-28) in naïve patients to 16 (12-25) in established patients (Table I). On average, in the year of follow up $47.9 \%$ and $56.3 \%$ of INR determinations in naïve and established patients, respectively, resulted within the recommended range (2.0-3.0) (Table II).

Mean percentage of INR determination below the recommended range was higher than mean percentage of INR determination above the recommended range for both naïve and established patients (Table II).

\begin{tabular}{lcccc}
\hline & INR & $\begin{array}{c}\text { Mean } \\
(\%)\end{array}$ & $\begin{array}{c}\text { Median } \\
(\%)\end{array}$ & $\begin{array}{c}\text { Percentile } \\
\text { 25-percentile 75 (\%) }\end{array}$ \\
\hline $\begin{array}{l}\text { VKA-naïve } \\
\text { patients }\end{array}$ & $<2.0$ & 35.4 & 28.8 & $15.4-47.9$ \\
& $2.0-3.0$ & 47.9 & 50.0 & $33.3-66.7$ \\
& $>3.0$ & 16.7 & 13.3 & $0.0-25.0$ \\
VKA- & $<2.0$ & 25.7 & 20.0 & $7.7-36.4$ \\
established & $2.0-3.0$ & 56.3 & 58.3 & $42.5-73.1$ \\
patients & $>3.0$ & 18.0 & 14.3 & $4.0-26.7$ \\
\hline
\end{tabular}

\section{Table II}

Percentages of INR determinations by range in naive and established VKAs treated patients

\begin{tabular}{ccc|cc}
\hline \multirow{2}{*}{$\begin{array}{c}\text { Adherence } \\
(\%)\end{array}$} & \multicolumn{2}{c|}{ VKA-naïve } & \multicolumn{2}{c}{ VKA-established } \\
\cline { 2 - 5 } & Nr. of patients (\%) & In-range INR (\%) & Nr. of patients (\%) & In-range INR (\%) \\
\hline $0-9$ & $830(27.0)$ & 34.3 & $1,014(13.1)$ & 47.6 \\
$10-19$ & $289(9.4)$ & 49.0 & $616(7.9)$ & 52.4 \\
$20-29$ & $271(8.8)$ & 49.6 & $699(9.0)$ & 54.1 \\
$30-39$ & $218(7.1)$ & 50.0 & $539(6.9)$ & 55.9 \\
$40-49$ & $225(7.3)$ & 52.9 & $606(7.8)$ & 55.6 \\
$50-59$ & $243(7.9)$ & 51.0 & $801(10.3)$ & 58.4 \\
$60-69$ & $197(6.4)$ & 55.5 & $698(9.0)$ & 58.7 \\
$70-79$ & $175(5.7)$ & 53.4 & $487(6.3)$ & 58.7 \\
$80-89$ & $152(4.9)$ & 55.7 & $500(6.4)$ & 60.4 \\
$>90$ & $475(15.4)$ & 57.8 & $1,798(23.2)$ & 60.0 \\
Total & $3,075(100.0)$ & 47.9 & $7,758(100.0)$ & 56.3 \\
\hline
\end{tabular}

\section{Table III}

INR control and VKA treatment adherence in naive and established VKAs treated patients 


\section{Table IV}

INR control and VKA treatment adherence in naive and established VKAs treated patients (developed only on patients with a number of INR determinations between 25 and 75 percentile)

\begin{tabular}{ccccc}
\hline \multirow{2}{*}{$\begin{array}{c}\text { Adherence } \\
(\%)\end{array}$} & \multicolumn{2}{c|}{ VKA-naïve } & \multicolumn{2}{c}{ VKA-established } \\
\cline { 2 - 5 } & Nr. of patients (\%) & In-range INR (\%) & Nr. of patients (\%) & In-range INR (\%) \\
\hline $0-9$ & $255(19.2)$ & 46.2 & $465(10.2)$ & 53.1 \\
$10-19$ & $129(9.7)$ & 48.8 & $307(6.7)$ & 54.9 \\
$20-29$ & $132(9.9)$ & 52.0 & $406(8.9)$ & 57.5 \\
$30-39$ & $105(7.9)$ & 52.8 & $310(6.8)$ & 58.5 \\
$40-49$ & $112(8.4)$ & 55.0 & $381(8.4)$ & 57.8 \\
$50-59$ & $110(8.3)$ & 54.2 & $487(10.7)$ & 60.8 \\
$60-69$ & $93(7.0)$ & 56.3 & $451(9.9)$ & 60.3 \\
$70-79$ & $78(5.9)$ & 56.4 & $294(6.4)$ & 61.9 \\
$80-89$ & $73(5.5)$ & 54.5 & $322(7.1)$ & 62.1 \\
$>90$ & $244(18.3)$ & 59.5 & $1,139(25.0)$ & 62.4 \\
Total & $1,331(100.0)$ & 53.1 & $4,562(100.0)$ & 59.4 \\
\hline
\end{tabular}

Adherence to VKA treatment was poor both in naïve and established patients but higher in established patients $(53.7 \pm 33.5 \%$ versus $41.6 \pm$ $35.0 \%$ ). According to the distribution by levels of adherence (Table III), highest frequency of patients was displayed by the lowest category of adherence in naïve patients $(27.0 \%)$ and by the highest category of adherence in established patients $(23.2 \%)$.

Both naïve and established patients seemed to be homogenously distributed into different levels of adherence. Similar results were obtained when only patients with a number of INR determinations within 25 and 75 percentile were studied (Table IV).

Mean percentage of INR determinations within the recommended range (2.0-3.0) varied from $34.3 \%$ in naïve patients with lowest adherence $(0-9 \%)$ to $57.8 \%$ in those with highest adherence $(>90 \%)$ and from $47.6 \%$ in established patients with lowest adherence $(0-9 \%)$ to $60.0 \%$ in those with highest adherence $(>90 \%)$ (Table III). Results are presented in Figure 1.
When only patients with a number of INR determinations within 25 and 75 percentile were studied (Table IV), mean percentage of INR determinations within the recommended range (2.0-3.0) varied from $46.2 \%$ in naïve patients with lowest adherence (0-9\%) to $59.5 \%$ in those with highest adherence $(>90 \%)$ and from $53.1 \%$ in established patients with lowest adherence (0-9\%) to $62.4 \%$ in those with highest adherence $(>90 \%)$. Results are presented in Figure 2. Overall, $55,6 \%$ of the patients in analysis had less than $60 \%$ of INR determinations within the recommended range (2.0-3.0) during the year of follow up.

The multivariable median regression showed that anticoagulation control was related to adherence with VKA treatment $(+0.14 \%$ of the percentage of INR in range 2-3 for an increment of $1 \%$ of VKA treatment coverage, $\mathrm{p}<0.001)$, use of heparins $(-10.70 \%, \mathrm{p}<0.001)$, antiplatelet agents $(-6.14 \%, p<0.001)$, or concurrent antithrombotic therapy $(-15.81 \%, \mathrm{p}<0.001)$, and to number of INR determinations $(+0.06 \%$ of the percentage of
Figure 1

INR control and VKA treatment adherence in naive and established VKAs treated patients

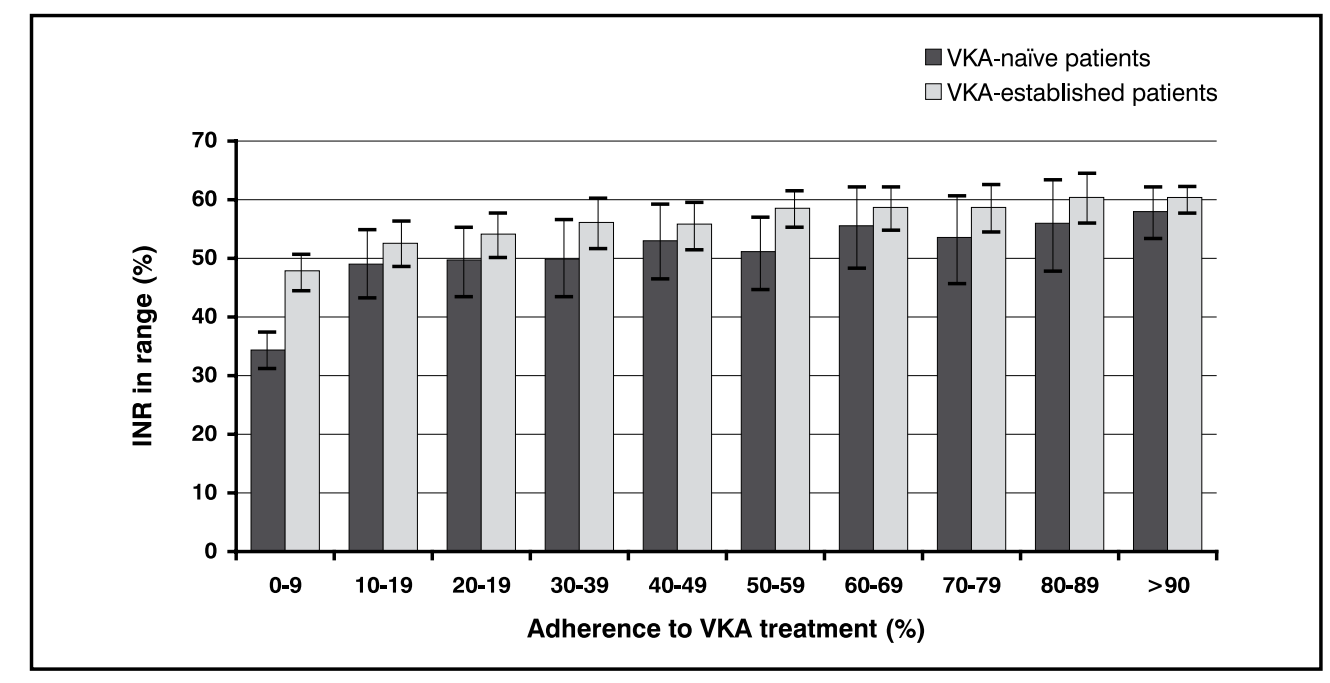




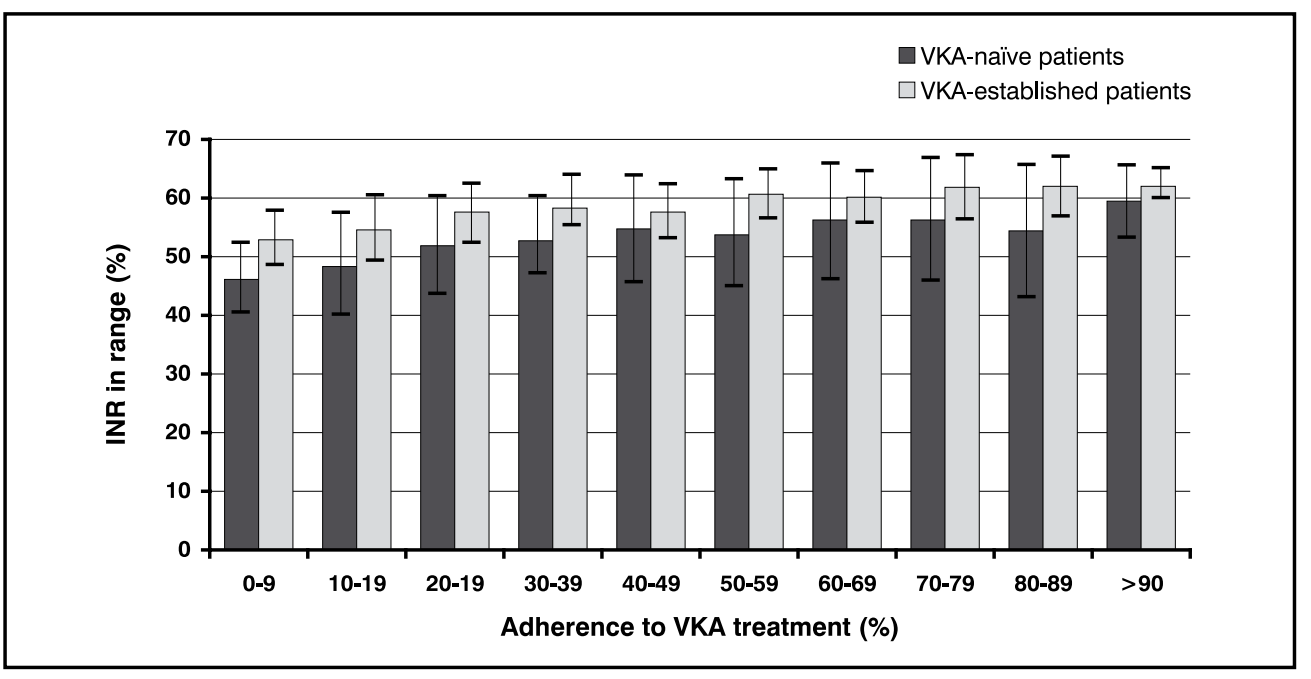

INR in range 2-3 for a one unit increment of INR determinations, $p=0.001)($ Table $\mathrm{V})$.

\section{DISCUSSION}

This study, in our knowledge the first in Italy to provide an evaluation about the degree of anticoagulation control in a large cohort of VKA treated patients as well as to explore the relationship between adherence to VKA treatment and anticoagulation control, showed that only $47.9 \%$ and $56.3 \%$ of INR determinations, in naïve and established patients respectively, were into the recommended range. Moreover, the percentage of INR determination below the recommended range was higher than the percentage of INR determination above the recommended range for both naïve and established patients. Other studies, performed in a clinical practice settings, have shown that patients were prone to spend more time with ratio below than above the therapeutic range $[11,12]$. These findings could be attributed to the effects of low dose of VKA treatment as a consequence of an overestimate risk of haemorrhage: physicians estimate the rate of intracranial bleeding related to the use of warfarin ten times higher than the rate reported in the literature [13]. A recent systematic review [8] found a strong association between anticoagulation intensity and outcomes: the risk of haemorrhage significantly increased when the INR exceeded 3, while the risk of thromboembolism was greatest when the INR was below 2 . When both haemorrhagic and thromboembolic events are considered, the data show that patients were safer with a ratio slightly above, rather than below, the therapeutic range of 2-3 [8]. Physicians should be aware of this finding and should adjust their clinical practices accordingly, by aggressively correcting subtherapeutic ratios and avoiding overreaction to ratios that narrowly exceed 3 .

Adherence to VKA treatment, the second aspect that we analysed, was poor both in naïve and established patients and, consequently, the anticoagulation control is poor. Also in patients with the highest adherence to VKA treatment, only about $60 \%$ of INR determinations were into the recommended range. It is possible that we have overestimated the non adherence to treatment since in clinical situations like deep venous thromboembolism as well as pulmonary embolism the length of VKA treatment was time-limited (weeks or months) and not chronically used. On the other hand, for the most common indications for anticoagulation, maximising the length of time at which a patient's international normalised ratio is in the therapeutic range of 2-3 should minimise the risk of both haemorrhagic and thromboembolic events [8]. In our work, factors positively related to anticoagulation control were adherence to treatment and frequency of INR determination, while a concurrent prescription of other antithrombotic drugs was negatively related to anticoagulation control. Our results seem to be in agreement with previous reports that evidenced the role of various factors, such as co-medications or chronic care management, on the intensity of anticoagulation control as well as patients outcomes $[14,15]$. Ensuring adequate monitoring of patients on oral anticoagulants and to maintain the intensity of anticoagulation within a safe

\begin{tabular}{lcccc}
\hline & $\beta$ & \multicolumn{2}{c}{$95 \%$ Cl } & p \\
\hline VKA treatment coverage (\%) & 0.14 & 0.13 & 0.15 & 0.000 \\
Gender (male) & 0.30 & -0.54 & 1.14 & 0.487 \\
Age (years) & 0.02 & -0.02 & 0.06 & 0.223 \\
Heparins & -10.70 & -12.03 & -9.37 & 0.000 \\
Antiplatelet agents & -6.14 & -7.38 & -4.90 & 0.000 \\
Other antithrombotic drugs & -15.81 & -24.13 & -7.48 & 0.000 \\
Nr. of INR determinations & 0.06 & 0.02 & 0.09 & 0.001 \\
\hline
\end{tabular}

Table V

Multivariable median regression on INR control in VKAs treated patients
Figure 2

INR control and VKA treatment adherence in naive and established VKAs treated patients (developed only on patients with a number of INR determinations between 25 and 75 percentile) 
and effective range is a crucial point for chronic care management to avoid an important cause of morbidity and mortality and a significant burden on health-care resources [16]: previous systematic reviews have shown that $4.9-7.7 \%$ of hospital admissions are related to adverse drug events and a median of $4.3 \%$ of admissions are considered preventable [17-19].

Findings of the present study must be interpreted in the light of some limitations. Reason for prescribing VKA treatment was not available, thus, as we have previously discussed, the evaluation of the appropriateness regarding the length of treatment is uncertain. Moreover, only records of INR determination reimbursed by the National Health Service were available. However, we believe that both these situations regard a minority of subjects.

In conclusion, the present study was based on participants recruited from the general population through the analysis of some databases of the National Health System. The link among the so-called administrative databases is simple to perform and does not require a specific epidemiological organisation, thus the cost is very low. We believe that a continuous monitoring of both VKA therapy and anticoagulation intensity in a practice clinical setting, as we have proposed, could contribute to improve the appropriateness of VKA treatment as well as the patient outcomes.

\section{STUDY GROUP}

Luca Degli Esposti (CliCon S.r.l. Health, Economics and Outcomes Research, Ravenna), Diego Sangiorgi (CliCon S.r.l. Health, Economics and Outcomes Research, Ravenna), Giuseppe Di Pasquale (Unità Operativa di Cardiologia. Ospedale Maggiore, Bologna), Gian Franco Gensini (Dipartimento di Area Critica Medico-Chirurgica, Università degli Studi di Firenze, Azienda Ospedaliero-Universitaria, Careggi. Fondazione Don Carlo Gnocchi, Onlus IRCCS, Impruneta, Firenze), Ido Iori (Medicina Interna I, Centro Emostasi e TrombosiStroke Unit, Azienda Ospedaliera A.S.M.N., Reggio Emilia), Stefano Buda (CliCon S.r.l. Health, Economics and Outcomes Research, Ravenna), Ezio Degli Esposti (CliCon S.r.l. Health, Economics and Outcomes Research, Ravenna), Dr. Paolo Lilli (Struttura Complessa Servizio Assistenza Farmaceutica, ASL3 Umbria), Dr. Marco Margioni (Direttore UOS Laboratorio Analisi Ospedale Valdarno, ASL 8 Arezzo).

\section{ACKNOWLEDGEMENTS}

This study was funded by Boehringer-Ingelheim Italy. The cooperation of Marco Ratti, EconD, MSc, Health Economics \& Outcomes Research Manager was gratefully acknowledged.

\section{REFERENCES}

1. Singer DE, Albers GW, Dalen JE, Fang MC, Go AS, Halperin JL et al. Antithrombotic therapy in atrial fibrillation: American College of Chest Physicians Evidence-Based Clinical Practice Guidelines (8th Edition). Chest 2008; 133 (6 Suppl): 546S-92S

2. Salem DN, O'Gara PT, Madias C, Pauker SG. American College of Chest Physicians. Valvular and structural heart disease: American College of Chest Physicians Evidence-Based Clinical Practice Guidelines (8th Edition). Chest 2008; 133 (6 Suppl): 593S-629S

3. Kearon C, Kahn SR, Agnelli G, Goldhaber S, Raskob GE, Comerota AJ et al. Antithrombotic therapy for venous thromboembolic disease: American College of Chest Physicians Evidence-Based Clinical Practice Guidelines (8th Edition). Chest 2008; 133 (6 Suppl): 454S-545S

4. EAFT Study Group. Secondary prevention in non-rheumatic atrial fibrillation after transient ischaemic attack or minor stroke. EAFT (European atrial fibrillation trial) Study Group. Lancet 1993; 342: 1255-62

5. Atrial Fibrillation Investigators. Risk factors for stroke and efficacy of antithrombotic therapy in atrial fibrillation: analysis of pooled data from five randomised controlled trials. Arch Intern Med 1994; 154: 1449-57

6. Van Walraven C, Gart RG, Singer DE, Laupacis A, Connolly S, Petersen P et al. Oral anticoagulants vs. aspirin in nonvalvular atrial fibrillation: an individual patient meta-analysis. JAMA 2002; 288: 2441-8

7. Hirsh J, Fuster V, Ansell J, Halperin JL; American Heart Association; American College of Cardiology Foundation. American Heart Association/American College of Cardiology Foundation guide to warfarin therapy. Circulation 2003; 107: 1692-711

8. Oake N, Jennings A, Forster AJ, Fergusson D, Doucette S, van Walraven C. Anticoagulation intensity and outcomes among patients prescribed oral anticoagulant therapy: a systematic review and meta-analysis. CMAJ 2008; 179 : $235-44$

9. Hylek EM, Heiman H, Skates SJ, Sheehan MA, Singer DE. Acetaminophen and other risk factors for excessive Warfarin anticoagulation. JAMA 1998; 279: 657-62 
10. Salobir B, Sabovic M, Peternel P. Intensity of long-term treatment with Warfarin is influenced by seasonal variations. Pathophysiol Haemost Thromb 2002; 32: 151-4

11. Van Walraven C, Oake N, Wells PS, Forster AJ. Burden of potentially avoidable anticoagulant-associated hemorrhagic and thromboembolic events in the elderly. Chest 2007; 131: 1508-15

12. Ansell J, Hollowell J, Pengo V, Martinez-Brotons F, Caro J, Drouet L. Descriptive analysis of the process and quality of oral anticoagulation management in real-life practice in patients with chronic non-valvular atrial fibrillation: the international study of anticoagulation management (ISAM). J Thromb Thrombolysis 2007; 23: 83-91

13. Gross CP, Vogel EW, Dhond AJ, Marple CB, Edwards RA, Hauch O et al. Factors influencing physicians' reported use of anticoagulation therapy in nonvalvular atrial fibrillation: a cross-sectional survey. Clin Ther 2003; 25: 1750-64

14. Penning van Beest FJ, Koerselman J, Herings RM. Quantity and quality of potential drug interactions with coumarin anticoagulants in the Netherlands. Pharm World Sci 2007; 29: 671-5

15. Drewes HW, Lambooij MS, Baan CA, Meijboom BR, Graafmans WC, Westert GP. Differences in patients outcomes and chronic care management of oral anticoagulant therapy: an explorative study. BMC Health Service Research 2011; 11: 18

16. Department of Health. An organization with a Memory. London: Department of Health, 2000

17. Winterstein AG, Sauer BC, Hepler CD, Poole C. Preventable drug-related Hospital admissions. Ann Pharmacother 2002; 36: 1238-48

18. Beijer HJM, de Blaey CJ. Hospitalisations caused by adverse drug reactions (ADR): a meta-analysis of observational studies. Pharm World Sci 2002; 24: 46-54

19. Howard RL, Avery AJ, Slavenburg S, Royal S, Pipe G, Lucassen P et al. Which drugs cause preventable admissions to hospital? A systematic review. Br J Clin Pharmacol 2007; 63: 136-47 